showed patent flow diverter(s) with or without stent(s). One patient had a 1 year follow up only which showed complete occlusion of the pseudoaneurysm with a patent flow diverter. No significant in-device stenosis was identified in any followup case.

Conclusion Use of flow diverters, in some cases in conjunction with (carotid) stents, is an effective treatment option for cervical carotid artery dissections, especially loop dissections with or without associated pseudo aneurysms.

Disclosures J. Singh: None. A. Kuhn: None. K. de Macedo Rodrigues: None. F. Massari: None. M. Gounis: 1; C; National Institutes of Health (NIH), the United States - Israel Binational Science Foundation, Anaconda, ApicBio, Axovant, Cerenovus, Cook Medical, Gentuity, Imperative Care, InNeuroCo, Magneto, Mic. 2; C; Cerenovus, Imperative Care, phenox, Medtronic Neurovascular, Route 92 Medical, Stryker Neurovascular. 4; C; Imperative Care, InNeuroCo and Neurogami. A. Puri: 1; C; NIH, Cerenovus, Stryker Neurovascular and Medtronic. 2; C; Stryker, Cerenovus, Medtronic, Microvention, QApel, Perfuze Medical, Arsenal Medical, Merit Medical. 4; C; InNeuroCo Inc, Galaxy therapeutics, Agile Medical, Perfuze medical and NTI.

\section{P-040 MAJOR COMPLICATIONS OF DURAL VENOUS SINUS STENTING FOR IDIOPATHIC INTRACRANIAL HYPERTENSION: CASE SERIES AND MANAGEMENT CONSIDERATIONS}

${ }^{1} \mathrm{R}$ Townsend*, ${ }^{2} \mathrm{~A}$ Jost, ${ }^{3} \mathrm{M}$ Amans, ${ }^{4} \mathrm{~F}$ Hui, ${ }^{5} \mathrm{M}$ Bender, ${ }^{6} \mathrm{~S}$ Satti, ${ }^{7} \mathrm{R}$ Maurer, ${ }^{8} \mathrm{~K}$ Liu, ${ }^{9} \mathrm{~W}$ Brinjikji, ${ }^{1} \mathrm{~K}$ Fargen. ${ }^{1}$ Neurosurgery, Wake Forest, Winston salem, NC; ${ }^{2}$ Wake Forest, Winston salem, NC; ${ }^{3}$ Neurosurgery, University of California-San Francisco, San Francisco, CA; ${ }^{4}$ Neurosurgery, Johns Hopkins Hospital, Baltimore, MD; ${ }^{5}$ University of Rochester Medical Center, Rochester, NY; ${ }^{6}$ Christiana Care Health System, Newark, DE; ${ }^{7}$ Penn State Health, Hershey, PA; ${ }^{8}$ University of Southern California, Los Angeles, CA; ${ }^{9}$ Mayo Clinic, Rochester, MN

\subsection{6/neurintsurg-2021-SNIS.76}

Introduction Venous sinus stenting (VSS) is a safe, effective, and increasingly popular treatment option for selected patients with idiopathic intracranial hypertension (IIH). Serious complications associated with VSS are rarely reported.

Methods Serious complications after VSS were identified retrospectively from multicenter databases. The cases are presented and management strategies are discussed.

Cases Six major acute and chronic complications after VSS were selected from a total of 811 VSS procedures and 1466 venograms for IIH. These included an acute subdural hematoma from venous extravasation, cases of both intraprocedural and delayed stent thrombosis, an ultimately fatal cerebellar hemorrhage resulting in acute obstructive hydrocephalus, venous microcatheter perforation during venography and manometry, and a patient who developed SAH and SDH after cerebellar cortical vein perforation. The 6 cases are reviewed and learning points regarding complication avoidance and management are presented.

Conclusion We report on 6 rare, major complications after VSS for IIH. Familiarity with these potential complications and appropriate timely management may allow for good clinical outcomes.

Disclosures R. Townsend: None. A. Jost: None. M. Amans: None. F. Hui: None. M. Bender: None. S. Satti: None. R. Maurer: None. K. Liu: None. W. Brinjikji: None. K. Fargen: None.

\section{P-041 CHRONIC HEADACHES AND MIDDLE MENINGEAL ARTERY EMBOLIZATION}

J Catapano*, K Karahalios, V Srinivasan, J Baranoski, C Rutledge, T Cole, A Ducruet, F Albuquerque, A Jadhav. Neurosurgery, BNI, Phoenix, AZ

\subsection{6/neurintsurg-2021-SNIS.77}

Background The middle meningeal artery (MMA) has been implicated in chronic headaches, but no studies have examined the relationship between MMA embolization and headaches.

Methods Patients treated with MMA embolization for a chronic subdural hematoma (cSDH) (1/1/2018-12/31/2020) were retrospectively assessed. Patients with a Glasgow Coma Scale (GCS) score of 15 on discharge received a follow-up phone call to assess their history of chronic headache, defined as a headache $\geq 2$ years before the $\mathrm{cSDH}$ and symptoms $\geq 2$ days/month. A Headache Impact Test (HIT-6) was performed during the follow-up phone call. The primary outcome was resolution or improvement of headaches after embolization.

Results Of 76 patients undergoing MMA embolization for a cSDH during the study period, 56 (74\%) had a discharge GCS of 15 . Of these 56 patients, 46 (82\%) responded to a follow-up phone call and were analyzed (mean (SD) age, 68 (11) years; 36 (78\%) men and 10 (22\%) women). Nine
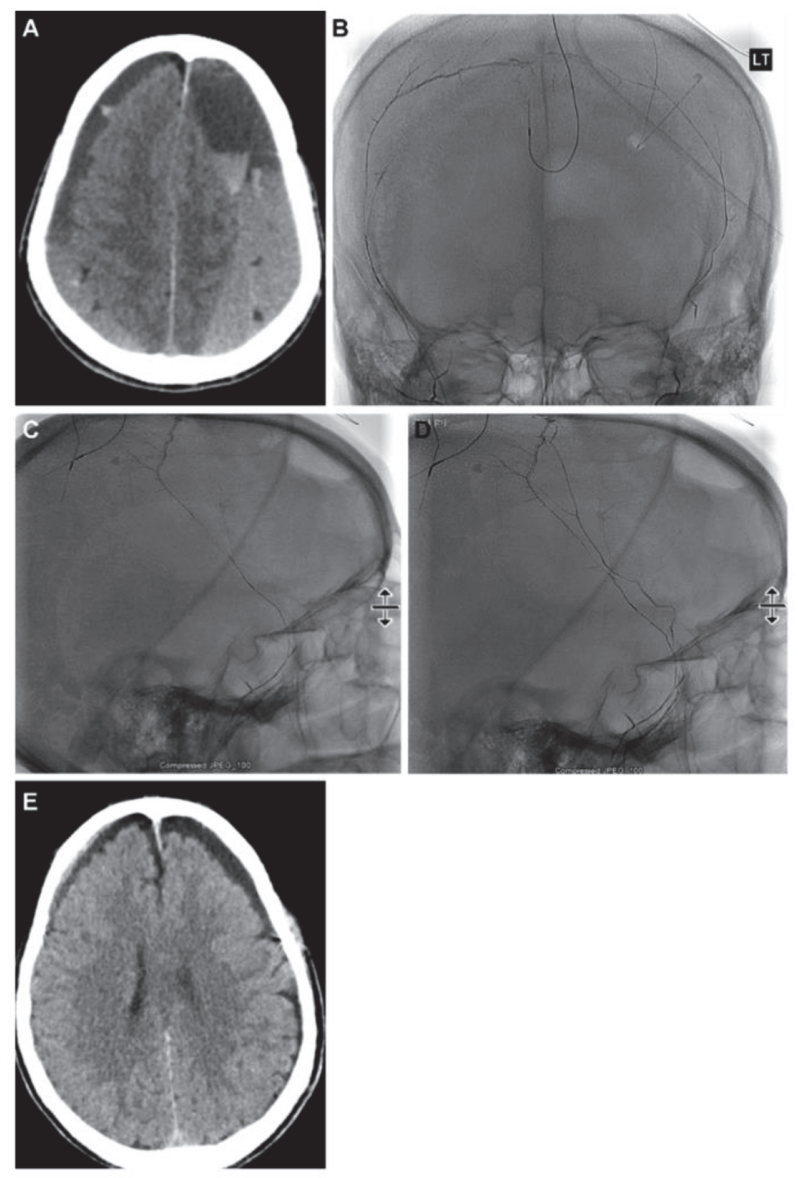

Abstract P-041 Figure 1 (A) Axial computed tomogram (CT) of the head showing bilateral chronic subdural hematomas (CSDHs). (B-D) Cerebral angiography images showing bilateral middle meningeal artery embolization with Onyx (views: B, un-subtracted posteroanterior; C, right lateral, D, left lateral). (E) Axial head $\mathrm{CT}$ at 30-day follow-up shows significant improvement of bilateral CSDHs. Used with permission from barrow neurological institute, Phoenix, Arizona 